\title{
Design of a double-decker coordination cage revisited to make new cages and exemplify ligand isomerism
}

\author{
Sagarika Samantray, Sreenivasulu Bandi and Dillip K. Chand ${ }^{*}$
}

\author{
Full Research Paper \\ Address: \\ Department of Chemistry, Indian Institute of Technology Madras, \\ Chennai 600036, India \\ Email: \\ Dillip K. Chand* - dillip@iitm.ac.in \\ * Corresponding author \\ Keywords: \\ anion binding; double-decker cage; ligand isomerism; macrocycles; \\ palladium; self-assembly; supramolecular
}

Beilstein J. Org. Chem. 2019, 15, 1129-1140. doi:10.3762/bjoc.15.109

Received: 06 March 2019

Accepted: 08 May 2019

Published: 21 May 2019

This article is part of the thematic issue "Novel macrocycles - and old ones doing new tricks".

Guest Editor: W. Jiang

(C) 2019 Samantray et al.; licensee Beilstein-Institut. License and terms: see end of document.

\begin{abstract}
The complexation study of cis-protected and bare palladium(II) components with a new tridentate ligand, i.e., pyridine-3,5diylbis(methylene) dinicotinate (L1) is the focus of this work. Complexation of cis- $\mathrm{Pd}(\mathrm{tmeda})\left(\mathrm{NO}_{3}\right)_{2}$ with $\mathbf{L 1}$ at a 1:1 or 3:2 ratio produced $[\mathrm{Pd}(\mathrm{tmeda})(\mathbf{L 1})]\left(\mathrm{NO}_{3}\right)_{2}(\mathbf{1 a})$. The reaction mixture obtained at 3:2 ratio upon prolonged heating, produced a small amount of $\left.\left[\mathrm{Pd}_{3} \text { (tmeda }\right)_{3}(\mathbf{L 1})_{2}\right]\left(\mathrm{NO}_{3}\right)_{6}(\mathbf{2 a})$. Complexation of $\mathrm{Pd}\left(\mathrm{NO}_{3}\right)_{2}$ with $\mathbf{L 1}$ at a 1:2 or $3: 4$ ratios afforded $\left[\mathrm{Pd}(\mathbf{L 1})_{2}\right]\left(\mathrm{NO}_{3}\right)_{2}(\mathbf{3 a})$ and $\left[\left(\mathrm{NO}_{3}\right)_{2} @ \mathrm{Pd}_{3}(\mathbf{L 1})_{4}\right]\left(\mathrm{NO}_{3}\right)_{4}(\mathbf{4 a})$, respectively. The encapsulated $\mathrm{NO}_{3}{ }^{-}$ions of $\mathbf{4 a}$ undergo anion exchange with halides $\left(\mathrm{F}^{-}, \mathrm{Cl}^{-}\right.$ and $\mathrm{Br}^{-}$but not with $\left.\mathrm{I}^{-}\right)$to form $\left[(\mathrm{X})_{2} @ \mathrm{Pd}_{3}(\mathbf{L 1})_{4}\right]\left(\mathrm{NO}_{3}\right)_{4} \mathbf{5 a}-\mathbf{7 a}$. The coordination behaviour of ligand $\mathbf{L 1}$ and some dynamic properties of these complexes are compared with a set of known complexes prepared using the regioisomeric ligand bis(pyridin-3ylmethyl)pyridine-3,5-dicarboxylate (L2). Importantly, a ligand isomerism phenomenon is claimed by considering complexes prepared from $\mathbf{L} \mathbf{1}$ and $\mathbf{L} 2$.
\end{abstract}

\section{Introduction}

Coordination-driven self-assembly is a convenient strategy for the construction of supramolecules of desired dimensions via simple synthetic procedures. Well-defined metal-ligand coordination bonds enable the construction of designer targeted molecules with ease. The use of a palladium(II) component for complexation with a non-chelating bi- or polydentate ligand (usually $\mathrm{N}$-donor ligands) is particularly advantageous for the construction of a variety of metallocages [1-5]. Complexation of cis-pro- tected palladium(II), i.e., (PdL') or bare palladium(II) with nonchelating bidentate ligands is known to afford a series of $(\mathrm{PdL})_{m} \mathrm{~L}_{m}$ or $\mathrm{Pd}_{m} \mathrm{~L}_{2 m}$-type self-assembled coordination complexes [5]. $\mathrm{Pd}_{2} \mathrm{~L}_{4}$-type cages are the simplest representatives among the $\mathrm{Pd}_{m} \mathrm{~L}_{2 m}$-type complexes, yet most utilised [5,6]. The $\mathrm{Pd}_{2} \mathrm{~L}_{4}$-type cages are well explored for the encapsulation of guests that are anionic [7-11], neutral [12-16], radical initiators [17], and drug molecules $[18,19]$. It is necessary to emphasize 
here that $\mathrm{Pd}_{2} \mathrm{~L}_{4}$-type cages contain a cavity. McMorran and Steel reported the first $\mathrm{Pd}_{2} \mathrm{~L}_{4}$-type cage and the anion binding ability of the cavity [20]. They also used a non-chelating tridentate ligand in an attempt to prepare a $\mathrm{Pd}_{3} \mathrm{~L}_{4}$-type double-decker coordination cage that would possess two cavities, if formed. However, the plan could not be executed as one of the coordinating atoms of the ligand remained unutilized [21]. Instead of the desired $\mathrm{Pd}_{3} \mathrm{~L}_{4}$ architecture, they observed a $\mathrm{PdL}_{2}$-type spirometallomacrocycle where bare palladium(II) is the juncture between two metallomacrocyclic rings. We report here a $\mathrm{Pd}_{3} \mathrm{~L}_{4}$-type cage prepared from $\mathrm{Pd}\left(\mathrm{NO}_{3}\right)_{2}$ and pyridine-3,5diylbis(methylene) dinicotinate (L1). We reported earlier the first $\mathrm{Pd}_{3} \mathrm{~L}_{4}$-type double-decker coordination cage using a simple tridentate "E" shaped ester-based ligand bis(pyridin-3ylmethyl)pyridine-3,5-dicarboxylate (L2) [22,23]. An additional feature in our design using $\mathbf{L} \mathbf{2}$ is the stoichiometrically controlled formation of $\mathrm{PdL}_{2}$-type spiro and $\mathrm{Pd}_{3} \mathrm{~L}_{4}$-type doubledecker complexes that is reversible under appropriate conditions. Subsequently, other research groups (Chand, Clever, Crowley and Yoshizawa groups) published $\mathrm{Pd}_{3} \mathrm{~L}_{4}$-type cages [24]. This design has been further explored by Crowley et al. for the synthesis of a $\mathrm{Pd}_{4} \mathrm{~L}_{4}$-type triple-decker cage [25]. The Clever research group reported a system in which two units of a double-decker cage are interlocked [26]. In this context, we revisited our earlier design of $\mathrm{Pd}_{3} \mathrm{~L}_{4}$-type cages to prepare a corresponding analogues cages using the new ligand $\mathbf{L 1}$ (that is a positional isomer or regioisomer of $\mathbf{L 2}$ ) in order to exemplify ligand isomerism.

Ligand isomerism includes metal complexes (at least two) having the same molecular formula but are composed of different positional isomers (regioisomers) of the ligand. Positional isomers (regioisomers) of a non-chelating ligand system capable of forming palladium(II) complexes of same molecular formula is a rare phenomenon [27-34]. Such palladium(II) complexes should represent the phenomenon of "ligand isomerism". We reported a family of $\mathrm{Pd}_{2} \mathrm{~L}_{4}$-type complexes that fits under the definition of ligand isomerism [34]. In the pursuit of ligand isomerism in $\mathrm{Pd}_{3} \mathrm{~L}_{4}$-type double-decker cages we intended to include our reported cage (prepared from palladium(II) and L2) $[22,23]$ and construct a new isomeric $\mathrm{Pd}_{3} \mathrm{~L}_{4}$-type complex. The complexation study of cis-protected and bare palladium(II) components with the new tridentate ligand, i.e., pyridine-3,5diylbis(methylene) dinicotinate (L1) is the focus of this work. In addition, the dynamic behavior as well as anion binding abilities of selected complexes are also probed. Ligand $\mathbf{L 1}$ is a constitutional isomer of ligand $\mathbf{L} 2$ [22,23] and is expected to exhibit similarities but also some differences in complexation behavior with palladium(II) components. There are also some similarities and some differences in the related properties of these complexes.

\section{Results and Discussion Design and synthesis of ligand L1}

The new ligand $\mathbf{L 1}$ was designed as a positional isomer (regioisomer) of the known ligand $\mathbf{L 2}$ (Figure 1). Each of these ligands has three pyridine moieties separated by two spacer moieties $\left(-\mathrm{CH}_{2} \mathrm{OC}(=\mathrm{O})-\right)$. Both ligands are semi-rigid/semiflexible due to the spacers' conformational mobility. The "E-shaped" conformation of the ligand that is suitable for the formation of the targeted $\mathrm{Pd}_{3} \mathrm{~L}_{4}$-type complex is shown here for clarity of discussion. In a given ligand, two of the pyridine rings are substituted in the 3-position and are terminal and symmetrically disposed with respect to the central/internal 3,5-disubstituted pyridine ring. The spacers are identical in both ligands, however, their orientations are reversed in ligand L1 as compared to the known ligand $\mathbf{L 2}$. The primary intention of the design of $\mathbf{L 1}$ was to have a positional isomer (regioisomer) of the ligand $\mathbf{L} 2$.

(i)<smiles>O=C(OCc1cncc(COC(=O)c2cccnc2)c1)c1cccnc1</smiles>

L1

(ii)

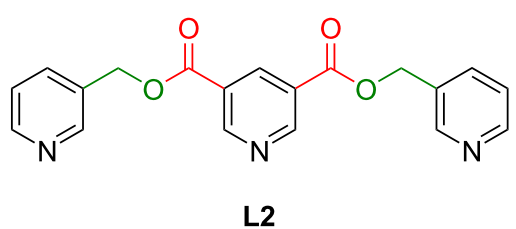

Figure 1: The ligands (i) $\mathbf{L} 1$ and (ii) $\mathbf{L} 2$ that are positional isomers (regioisomers).

The tridentate ligand pyridine-3,5-diylbis(methylene) dinicotinate (L1, Figure 1) was prepared by condensation of pyridine3,5-diyldimethanol [35] with nicotinoyl chloride hydrochloride in dry dichloromethane in the presence of triethylamine. The reaction mixture was stirred at room temperature for $24 \mathrm{~h}$ followed by aqueous work-up and column chromatography purification to afford pyridine-3,5-diylbis(methylene) dinicotinate (L1) as a white solid. The ligand was fully characterized by NMR spectroscopy and ESIMS techniques (Supporting Information File 1, Figures S1-S11). In addition, NOESY analysis was helpful in distinguishing the protons $\mathrm{H}_{\mathrm{a}}$ and $\mathrm{H}_{\mathrm{f}}$.

It is assumed that the electron density at the central pyridine ring in $\mathbf{L 1}$ (that is a lutidine derivative) should be higher than that at the central pyridine ring of $\mathbf{L} 2$ (that is a dinicotinate derivative) having electron-withdrawing carbonyl substituents. Also, the electron density at the terminal pyridine ring in $\mathbf{L 1}$ (that is a nicotinate derivative) should be lower than that at the 
terminal pyridine ring of $\mathbf{L 2}$ (that is a picolyl derivative). The electrostatic potential maps at the terminal and internal pyridine nitrogen calculated using DFT methods (Supporting Information File 1, Table S2), however, are found to be comparable. Nevertheless, it seemed interesting to check whether or not the subtle difference in the electron density at the pyridine $\mathrm{N}$ centers has any influence on the coordination behavior of the ligands.

\section{Complexation of palladium(II) components with ligand L1}

Complexation of $c i s$-protected palladium(II) was carried out with the ligand $\mathbf{L} \mathbf{1}$ at two different metal-to-ligand ratios (1:1 and $3: 2$ ). We also carried out the complexation of bare palla-
dium(II) with the ligand $\mathbf{L} \mathbf{1}$ at two different metal-to-ligand ratios (1:2 and 3:4). The complexation reactions performed in DMSO- $d_{6}$ allowed the monitoring of complex formation and those performed in DMSO were used for isolation of the complex by precipitation methods. The resulting complexes at specified ratios of the reactants are depicted in Scheme 1 and the details of the complexation behavior are described below.

\section{Complexation of cis-protected palladium(II) with ligand $\mathbf{L} \mathbf{1}$ at 1:1 metal-to-ligand ratio}

The addition of one equivalent of cis- $\mathrm{Pd}(\mathrm{tmeda})\left(\mathrm{NO}_{3}\right)_{2}$ to a clear solution of one equivalent of the ligand $\mathbf{L 1}$ in DMSO- $d_{6}$ produced a turbid mixture. However, a clear yellow solution was obtained upon stirring the mixture at $90{ }^{\circ} \mathrm{C}$ for 5 min or at
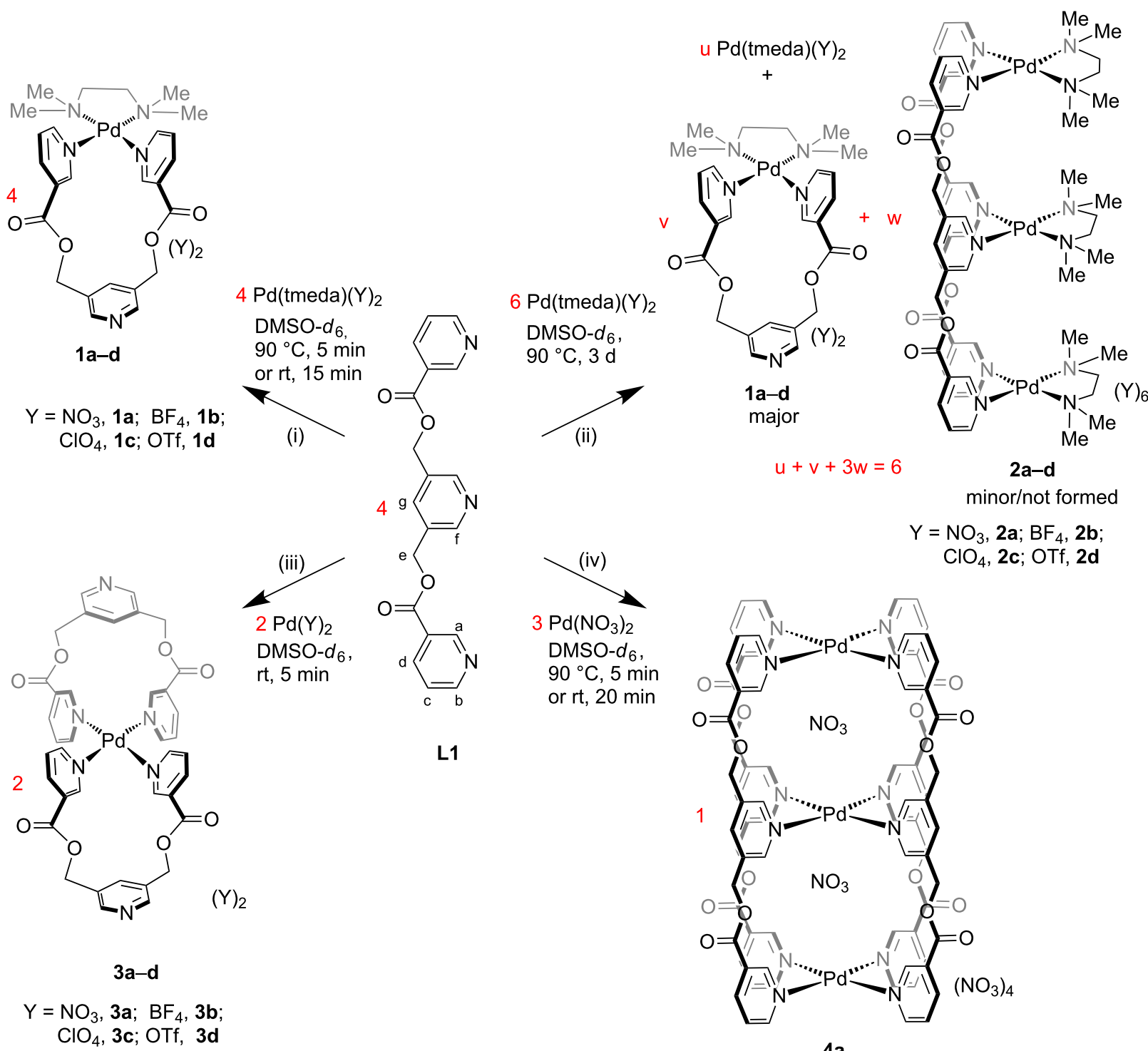

$4 a$

Scheme 1: (i)/(ii) Complexation of $\mathrm{Pd}\left(\right.$ tmeda) $(\mathrm{Y})_{2}$ with the ligand $\mathbf{L} 1$ at $1: 1$ and 2:3 metal-to-ligand ratios, respectively; (iii)/(iv) complexation of $\mathrm{Pd}(\mathrm{Y})_{2}$ with the ligand $\mathbf{L 1}$ at 1:2 and 3:4 metal-to-ligand ratios, respectively. For (i)/(ii)/(iii): ${\mathrm{Y}=\mathrm{NO}_{3}{ }^{-}, \mathrm{BF}_{4}^{-}, \mathrm{ClO}_{4}{ }^{-} \text {, or OTf }}^{-}(\mathbf{2 b}$ was not formed). 
$\mathrm{rt}$ for $15 \mathrm{~min}$. The reaction was repeated in DMSO and the $\left(\mathrm{PdL}^{\prime}\right)$ L-type complex $[\mathrm{Pd}(\mathrm{tmeda})(\mathbf{L} \mathbf{1})]\left(\mathrm{NO}_{3}\right)_{2}(\mathbf{1} \mathbf{a}$, Scheme 1(i)) was isolated from the reaction mixture by a precipitation method that is described in the experimental section. The ${ }^{1} \mathrm{H}$ NMR spectrum of the solution showed formation of a single discrete complex (Figure 2(ii)). Counter-anion $\left(\mathrm{BF}_{4}^{-}, \mathrm{ClO}_{4}^{-}\right.$and $\left.\mathrm{OTf}^{-}\right)$variation was also carried out to successfully prepare a series of complexes $[\mathrm{Pd}(\mathrm{tmeda})(\mathbf{L 1})]\left(\mathrm{BF}_{4}\right)_{2}$ (1b); $[\mathrm{Pd}($ tmeda $)(\mathbf{L 1})]\left(\mathrm{ClO}_{4}\right)_{2}(\mathbf{1 c})$; $[\mathrm{Pd}($ tmeda $)(\mathbf{L 1})](\mathrm{OTf})_{2}$ (1d). The complexes 1a-d were prepared by mixing the corresponding metal component $\operatorname{Pd}($ tmeda $)(\mathrm{Y})_{2}$ with the ligand $\mathbf{L} 1$ where $\mathrm{Y}=\mathrm{NO}_{3}{ }^{-}, \mathrm{BF}_{4}{ }^{-}, \mathrm{ClO}_{4}{ }^{-}$and $\mathrm{OTf}^{-}$. The metal components were prepared in situ by reacting $\mathrm{Pd}($ tmeda $)(\mathrm{Cl})_{2}$ with $\mathrm{AgY}$ in DMSO- $d_{6}$ followed by separation of the precipitated $\mathrm{AgCl}$.

The complex 1a was characterized by various NMR techniques (Supporting Information File 1, Figures S12-S16). The ${ }^{1} \mathrm{H}$ NMR spectrum of compound 1a showed single set of peaks (Figure 2(ii)) characterized by complexation-induced downfield shifts of protons belonging to the terminal pyridines $\left(\Delta \delta=0.77,0.52\right.$, and $0.29 \mathrm{ppm}$ for $\mathrm{H}_{\mathrm{a}}, \mathrm{H}_{\mathrm{b}}$, and $\mathrm{H}_{\mathrm{c}}$, respectively) as compared to the free ligand $\mathbf{L 1}$. The peak positions of $\mathrm{H}_{\mathrm{f}}$ and $\mathrm{H}_{\mathrm{g}}$ remained unchanged which indicated that the central pyridine ring is not involved in the complexation. The ${ }^{1} \mathrm{H}$ NMR spectra of compounds $\mathbf{1 b}, \mathbf{1 c}$ and $\mathbf{1 d}$ are very much comparable to that of 1a (Supporting Information File 1, Figure S17). One of the coordination sites of the ligand $\mathbf{L 1}$ thus remained unutilized in these mononuclear complexes.

The ESIMS data of the compounds $\mathbf{1 b}, \mathbf{1} \mathbf{c}$ and $\mathbf{1 d}$ confirmed the formation of mononuclear complexes (Supporting Information
File 1, Figures S18-S20). As an example, the ESIMS spectrum of compound 1b (Supporting Information File 1, Figure S18) showed isotopic peak patterns at $m / z 658.14$ and 285.57, respectively, which correspond to the cationic fragments $\left[\mathbf{1 b}-\mathrm{BF}_{4}\right]^{+}$ and $\left[1 \mathbf{b}-2 \mathrm{BF}_{4}\right]^{2+}$ that are formed due to the loss of one and two units of counter anions from $\mathbf{1 b}$. The experimental and theoretical peak patterns were found to be in agreement. The data of 1c and 1d are given in Supporting Information File 1.

\section{Complexation of cis-protected palladium(II) with ligand $\mathbf{L 1}$ at a 3:2 metal-to-ligand ratio}

The addition of three equivalents of cis-Pd(tmeda) $\left(\mathrm{NO}_{3}\right)_{2}$ to a clear solution of two equivalents of ligand $\mathbf{L} 1$ in DMSO- $d_{6}$ produced a turbid mixture. However, a clear yellow solution was obtained upon stirring the mixture at $90{ }^{\circ} \mathrm{C}$ for $5 \mathrm{~min}$. The progress of the complexation reaction was monitored by ${ }^{1} \mathrm{H}$ NMR spectroscopy. We targeted a $\mathrm{Pd}_{3} \mathrm{~L}{ }_{3} \mathrm{~L}_{2}$-type complex [36], i.e., $\left[\mathrm{Pd}_{3}(\text { tmeda })_{3}(\mathbf{L 1})_{2}\right]\left(\mathrm{NO}_{3}\right)_{6}$ (2a, Scheme 1(ii)). However, the NMR spectrum showed the formation of $[\mathrm{Pd}(\mathrm{tmeda})(\mathbf{L 1})]\left(\mathrm{NO}_{3}\right)_{2}$ (1a) and uncomplexed cis-Pd(tmeda) ${ }^{2+}$. The reaction was allowed to continue where upon the integration ratios of the peaks corresponding to $\mathrm{H}_{\mathrm{f}}$ and $\mathrm{H}_{\mathrm{g}}$ were lower than expected and that of $\mathrm{H}_{\mathrm{d}}$ was higher than expected. In addition, a new peak was observed at around $9.15 \mathrm{ppm}$ (Figure 2(iii)). Careful analysis of the data led us to propose the formation of a minor proportion of $\mathbf{2 a}$ along with a major proportion of $1 \mathbf{a}$ and unutilized cis-Pd(tmeda) ${ }^{2+}$ remaining in solution. The peaks assigned to $\mathrm{H}_{\mathrm{f}}$ and $\mathrm{H}_{\mathrm{g}}$ of $\mathbf{2 a}$ are shifted downfield compared to those of $\mathrm{H}_{\mathrm{f}}$ and $\mathrm{H}_{\mathrm{g}}$ in 1a whereas other signals of 2 a merged with the respective signals of $1 \mathbf{a}$. The observed downfield shift of the $\mathrm{H}_{\mathrm{f}}$ signal in $\mathbf{2 a}$ is complexation-induced and found to have a unique position. The downfield shift
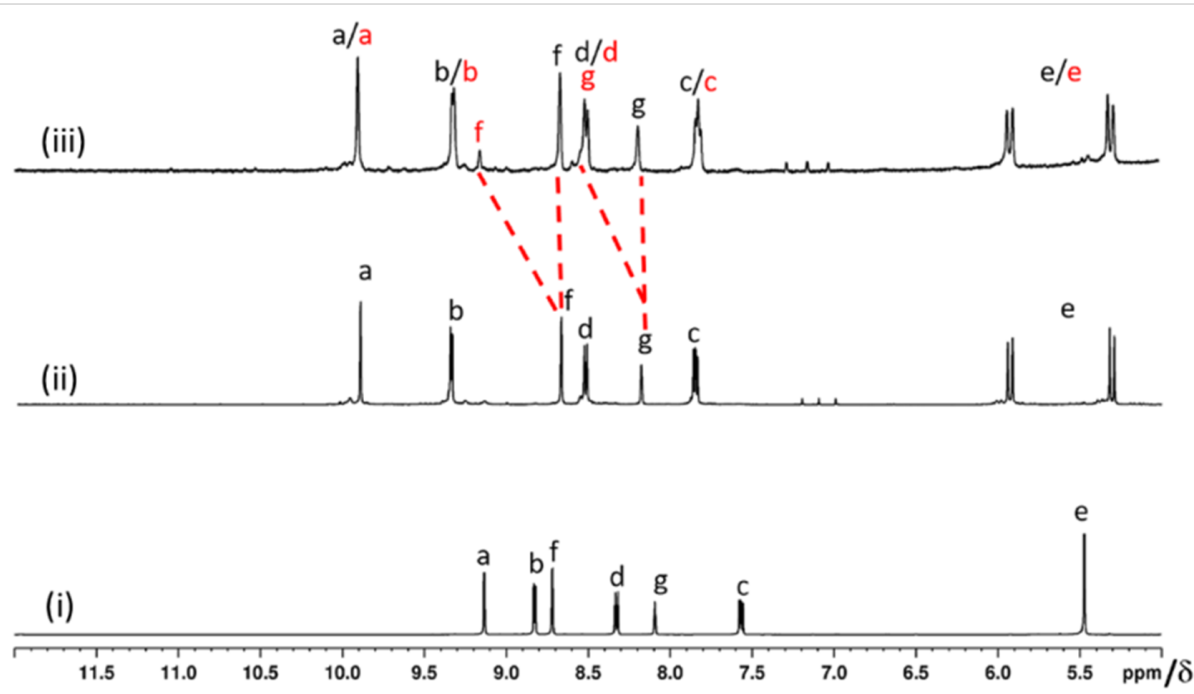

Figure 2: Partial ${ }^{1} \mathrm{H}$ NMR spectra in DMSO- $d_{6}$ for (i) $\mathbf{L 1}$, (ii) $[\mathrm{Pd}(\mathrm{tmeda})(\mathbf{L 1})]\left(\mathrm{NO}_{3}\right)_{2}(\mathbf{1 a})$ and (iii) a mixture of $[\mathrm{Pd}(\mathrm{tmeda})(\mathbf{L 1})]\left(\mathrm{NO}_{3}\right)_{2}(\mathbf{1 a})$ and $\left[\mathrm{Pd}_{3}(\mathrm{tmeda})_{3}(\mathrm{~L} \mathbf{1})_{2}\right]\left(\mathrm{NO}_{3}\right)_{6}(\mathbf{2 a})$. 
of the $\mathrm{H}_{\mathrm{g}}$ signal in $\mathbf{2 a}$ could not be induced by complexation and is best described by considering an anisotropy effect of the nearby carbonyl groups the ligand strand. The $\mathrm{H}_{\mathrm{g}}$ signal of $\mathbf{2 a}$, however, merged with the $\mathrm{H}_{\mathrm{d}}$ signal of $\mathbf{1 a}$.

Subsequently, anion variation $\left(\mathrm{BF}_{4}^{-}, \mathrm{ClO}_{4}{ }^{-}\right.$and $\left.\mathrm{OTf}^{-}\right)$was carried out in anticipation of the trinuclear products $\mathbf{2 b - d}$ (Scheme 1). Complexation of the metal component $\operatorname{Pd}($ tmeda $)(\mathrm{Y})_{2}$ with the ligand $\mathbf{L} 1$ were carried out where $\mathrm{Y}=$ $\mathrm{NO}_{3}{ }^{-}, \mathrm{BF}_{4}{ }^{-}, \mathrm{ClO}_{4}{ }^{-}$and $\mathrm{OTf}^{-}$. The metal components were prepared in situ by reacting $\mathrm{Pd}(\mathrm{tmeda})(\mathrm{Cl})_{2}$ with $\mathrm{AgY}$ in DMSO- $d_{6}$ followed by separation of the precipitated $\mathrm{AgCl}$. The ${ }^{1} \mathrm{H}$ NMR spectra of the samples confirmed the formation of mononuclear complexes 1b-d at initial stages (Supporting Information File 1, Figures S22-S24). All reactions were allowed to continue and their progress was monitored by ${ }^{1} \mathrm{H}$ NMR spectroscopy. The peak positions in the ${ }^{1} \mathrm{H}$ NMR spectrum of the sample containing $\mathrm{BF}_{4}{ }^{-}$as counter anion remained unchanged but the same for the samples containing $\mathrm{ClO}_{4}{ }^{-}$and $\mathrm{OTf}^{-}$behaved in a manner very similar to the case of $\mathrm{NO}_{3}{ }^{-}$. A new peak was observed at around $9.10 \mathrm{ppm}$ corresponding to $\mathrm{H}_{\mathrm{f}}$ in each case. When integration ratio of $\mathrm{H}_{\mathrm{a}}$ is taken as 1.0 the integration ratio of $\mathrm{H}_{\mathrm{f}}$ for $\mathbf{1 d}$ and $\mathbf{2 d}$ in the mixture were found to be $\approx 0.8$ and $\approx 0.2$, respectively. It may be noted here that a comparable trinuclear complex of ligand $\mathbf{L} 2$, however, did not form [23].

ESIMS data were collected in anticipation of detecting the trinuclear complexes (Supporting Information File 1, Figures S25 and S26). Isotopic peak patterns at $\mathrm{m} / z 391.55$ corresponding to the fragment $\left[2 \mathrm{c}-4 \mathrm{ClO}_{4}\right]^{4+}$ confirmed the existence of the trinuclear complex 2c. Similarly, isotopic peak patterns at $\mathrm{m} / \mathrm{z}$ 2111.08 corresponding to the fragment $[\mathbf{2 d}-\mathrm{OTf}]^{+}$confirmed the existence of trinuclear complex $\mathbf{2 d}$. The experimental and theoretical patterns were found to be in agreement.

\section{Complexation of bare palladium(II) with ligand $\mathbf{L} 1$ at a $1: 2$ metal-to-ligand ratio}

The sample of $\mathrm{Pd}\left(\mathrm{NO}_{3}\right)_{2}$ used in this work was commercially acquired. A solution containing one equivalent of $\mathrm{Pd}\left(\mathrm{NO}_{3}\right)_{2}$ in DMSO- $d_{6}$ was added to a separate solution containing two equivalents of ligand $\mathbf{L 1}$ in DMSO- $d_{6}$. The ${ }^{1} \mathrm{H}$ NMR spectrum of the resulting solution showed formation of a single discrete complex. The reaction was repeated in DMSO and the $\mathrm{PdL}_{2}-$ type complex $\left[\mathrm{Pd}(\mathbf{L 1})_{2}\right]\left(\mathrm{NO}_{3}\right)_{2}(\mathbf{3 a}$, Scheme 1c) was isolated from the reaction mixture by precipitation as described in the experimental section. Counter-anion $\left(\mathrm{BF}_{4}{ }^{-}, \mathrm{ClO}_{4}{ }^{-}\right.$and $\left.\mathrm{OTf}^{-}\right)$ variation was also carried out to successfully prepare a series of complexes $\left[\mathrm{Pd}(\mathbf{L 1})_{2}\right]\left(\mathrm{BF}_{4}\right)_{2}(\mathbf{3 b}),\left[\mathrm{Pd}(\mathbf{L 1})_{2}\right]\left(\mathrm{ClO}_{4}\right)_{2}(\mathbf{3 c})$, and $\left[\mathrm{Pd}(\mathbf{L 1})_{2}\right](\mathrm{OTf})_{2}(\mathbf{3 d})$. These complexes were prepared by complexation of $\mathrm{Pd}(\mathrm{Y})_{2}$ with the ligand $\mathbf{L 1}$ where $\mathrm{Y}=\mathrm{BF}_{4}{ }^{-}, \mathrm{ClO}_{4}{ }^{-}$, and $\mathrm{OTf}^{-}$. It is important to note that $\mathrm{Pd}(\mathrm{Y})_{2}$ solutions were prepared by reacting $\mathrm{PdI}_{2}$ with $\mathrm{AgY}$ and the precipitated $\mathrm{AgI}$ was removed by filtration. Following this procedure, the presence of iodide as impurity could not be ruled out but its presence was found to not influence the formation of the targeted complex. In contrast, the presence of chloride remaining as impurity when $\mathrm{PdCl}_{2}$ was reacted with $\mathrm{AgY}$ to prepare $\mathrm{Pd}(\mathrm{Y})_{2}$, contaminated $\mathrm{Pd}(\mathrm{Y})_{2}$ and produced upon complexation with $\mathbf{L} \mathbf{1}$ complexes 3a-d along with some other products. The choice of $\mathrm{PdI}_{2}$ is on the basis of our previous experience from related cages [23]. The complex 3a was characterized by various NMR techniques (Supporting Information File 1, Figures S27-S31). The ${ }^{1} \mathrm{H}$ NMR spectrum of compound 3a showed a single set of peaks (Figure 3 ) featured with complexation-induced downfield shifts of protons belonging to the terminal pyridines $(\Delta \delta=$

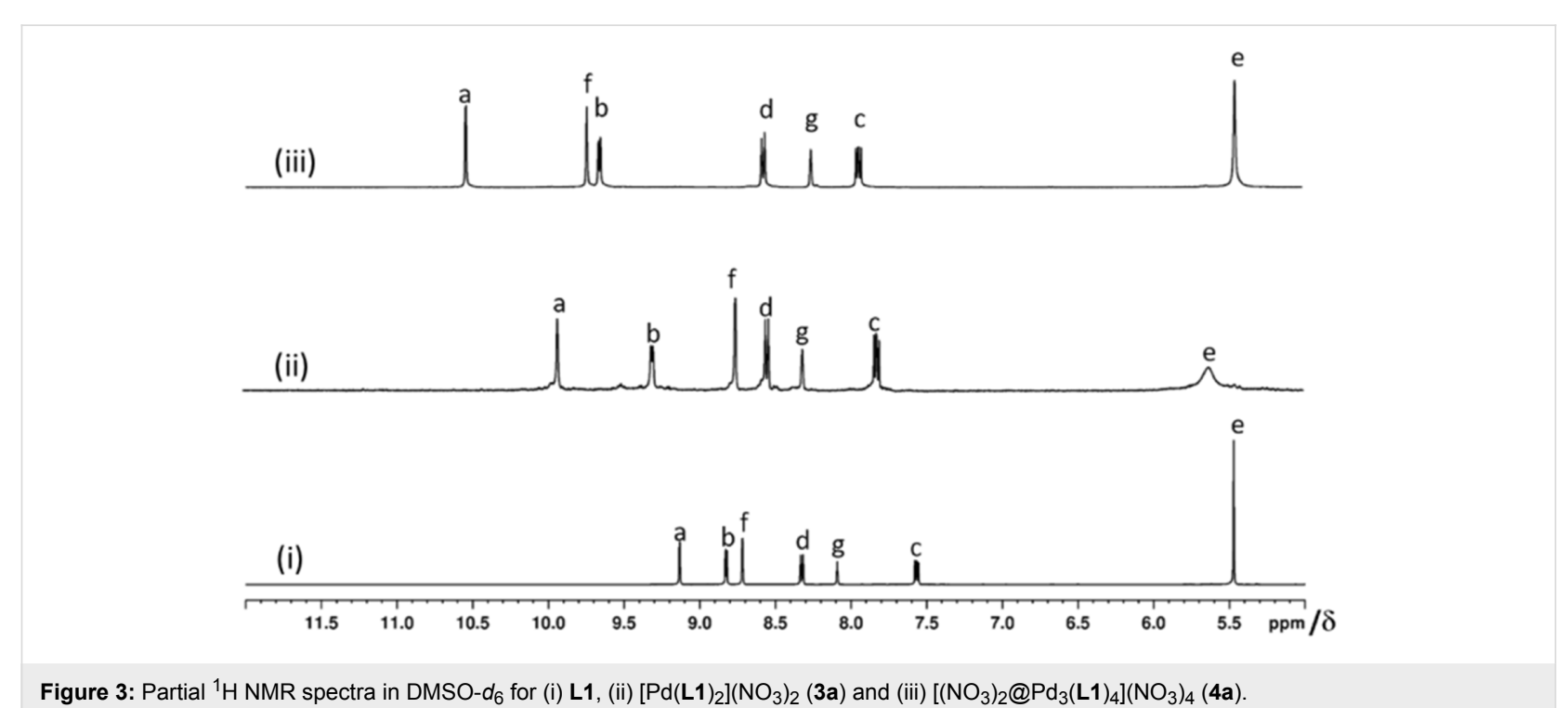

Figure 3: Partial ${ }^{1} \mathrm{H}$ NMR spectra in DMSO- $d_{6}$ for (i) L1, (ii) $\left[\mathrm{Pd}(\mathrm{L1})_{2}\right]\left(\mathrm{NO}_{3}\right)_{2}(3 a)$ and (iii) $\left[\left(\mathrm{NO}_{3}\right)_{2} @ \mathrm{Pd}_{3}(\mathbf{L} 1)_{4}\right]\left(\mathrm{NO}_{3}\right)_{4}(4 \mathrm{a})$. 
0.79 , and $0.47 \mathrm{ppm}$ for $\mathrm{H}_{\mathrm{a}}$, and $\mathrm{H}_{\mathrm{b}}$, respectively) as compared to the free ligand $\mathbf{L} 1$.

The peak position of $\mathrm{H}_{\mathrm{f}}$ did not change indicating that the central pyridine is not involved in the complexation. The ${ }^{1} \mathrm{H}$ NMR spectra of compounds $\mathbf{3 b}, \mathbf{3} \mathbf{c}$ and $\mathbf{3 d}$ are very much comparable to that of $\mathbf{3 a}$ (Supporting Information File 1, Figure S32). One of the coordination sites of the ligand L1 thus remained unutilized in these mononuclear complexes.

The ESIMS spectrum of compound 3a (Supporting Information File 1, Figure S33) showed isotopic peak patterns at $m / z 866.10$ and 402.05 , respectively, which corresponds to the cationic fragments $\left[\mathbf{3 a}-\mathrm{NO}_{3}\right]^{+}$and $\left[\mathbf{3 a}-2 \mathrm{NO}_{3}\right]^{2+}$ that are formed due to the loss of one and two units of counter anions from $3 \mathbf{a}$. The experimental and theoretical peak patterns were found to be in agreement. The ESIMS spectrum of $\mathbf{3 b}$ is provided in Supporting Information File 1, Figure S34.

\section{Complexation of bare palladium(II) with ligand L1 at a 3:4 metal-to-ligand ratio}

A solution containing three equivalents of commercially acquired $\mathrm{Pd}\left(\mathrm{NO}_{3}\right)_{2}$ in DMSO- $d_{6}$ was added to the solution containing four equivalents of ligand $\mathbf{L} \mathbf{1}$ in DMSO- $d_{6}$. The ${ }^{1} \mathrm{H}$ NMR spectrum of the resulting solution recorded within 10 min showed a mixture of products. However, a single discrete complex was formed upon heating the solution at $90{ }^{\circ} \mathrm{C}$ for $5 \mathrm{~min}$ or upon stirring at $\mathrm{rt}$ for $20 \mathrm{~min}$. A careful analysis of the ${ }^{1} \mathrm{H}$ NMR spectrum revealed the existence of $\left[\mathrm{Pd}(\mathbf{L 1})_{2}\right]\left(\mathrm{NO}_{3}\right)_{2}(\mathbf{3 a})$ and $\left[\left(\mathrm{NO}_{3}\right)_{2} @ \mathrm{Pd}_{3}(\mathbf{L 1})_{4}\right]\left(\mathrm{NO}_{3}\right)_{4}(\mathbf{4 a})$ in the mixture (Supporting Information File 1, Figure S35a). The mononuclear complex $\mathbf{3 a}$ is proposed here as a kinetically controlled product and the trinuclear $\mathbf{4 a}$ as the thermodynamic product. The reaction was repeated in DMSO and the $\mathrm{Pd}_{3} \mathrm{~L}_{4}{ }^{-}$ type complex 4a (Scheme 1d) was isolated from the reaction mixture by precipitation as described in the experimental section. Complexation of $\mathrm{Pd}(\mathrm{Y})_{2}$ (prepared from $\mathrm{PdI}_{2}$ and $\mathrm{AgY}$, where $\mathrm{Y}=\mathrm{BF}_{4}{ }^{-}, \mathrm{ClO}_{4}{ }^{-}$, and $\mathrm{OTf}^{-}$) with the ligand $\mathbf{L 1}$ at a $3: 4$ ratio resulted in the formation of only mononuclear complexes $\mathbf{3 b}$-d (depicted in a later Scheme) and the unutilized proportion of $\mathrm{Pd}(\mathrm{Y})_{2}$ remained in solution. Thus, the counter ion nitrate has a determining role by acting as template for the cavities in the formation of the trinuclear complex 4a. It is proposed that the anion is essential to avoid charge repulsion between the metal centers in the ensuing cavities. However, the anions should be of fitting sizes only to get accommodated in the cavities so that discrete architectures are formed. Larger anions such as $\mathrm{BF}_{4}{ }^{-}$, $\mathrm{ClO}_{4}{ }^{-}$and $\mathrm{OTf}^{-}$are not accommodated in the cavities and not helpful as templates. The $\mathrm{Pd}\left(\mathrm{NO}_{3}\right)_{2}$ sample prepared from $\mathrm{PdCl}_{2}$ and $\mathrm{AgNO}_{3}$, contained chloride as impurity and resulted in a mixture of products along with the targeted $4 \mathbf{a}$ (Supporting
Information File 1, Figure S35b). The products in the mixture were identified as $\left[(\mathrm{Cl})\left(\mathrm{NO}_{3}\right) @ \mathrm{Pd}_{3}(\mathbf{L 1})_{4}\right]\left(\mathrm{NO}_{3}\right)_{4}\left(\mathbf{6 a} \mathbf{a}^{\prime}\right)$ and $\left[(\mathrm{Cl})_{2} @ \mathrm{Pd}_{3}(\mathbf{L 1})_{4}\right]\left(\mathrm{NO}_{3}\right)_{4}(\mathbf{6 a})$ and their proportion was found to depend on the amount of chloride as impurity. The influence of chloride on the product composition is discussed in a later section.

The complex 4a was characterized by various NMR techniques (Supporting Information File 1, Figures S37-S41). The ${ }^{1} \mathrm{H}$ NMR spectrum of compound $\mathbf{4 a}$ showed a single set of peaks (Figure 3 ) featured with complexation-induced downfield shifts of protons belonging to the terminal as well as to the central pyridine rings $\left(\Delta \delta=1.42,0.82,1.02 \mathrm{ppm}\right.$ for $\mathrm{H}_{\mathrm{a}}, \mathrm{H}_{\mathrm{b}}$, and $\mathrm{H}_{\mathrm{f}}$, respectively) as compared to the free ligand $\mathbf{L} 1$. The signal of $\mathrm{H}_{\mathrm{f}}$ also got downfield-shifted indicating that the central pyridine ring is involved in the complexation.

The ESIMS spectrum of compound 4a confirmed the formation of a trinuclear complex (Supporting Information File 1, Figure S42). Isotopic peak patterns are found at $\mathrm{m} / \mathrm{z} 982.04,634.03$ and 460.03, which correspond to the cationic fragments [4a $\left.2 \mathrm{NO}_{3}\right]^{2+},\left[\mathbf{4 a}-3 \mathrm{NO}_{3}\right]^{3+}$ and $\left[\mathbf{4 a}-4 \mathrm{NO}_{3}\right]^{4+}$ that are formed due to the loss of two, three and four units of counter anions from 4a. The experimental and theoretical peak patterns were found to be in agreement.

\section{DFT studies of the complexes}

The energy-minimized structures of $[\operatorname{Pd}(\operatorname{tmeda})(\mathbf{L} 1)]^{2+}$, $\left[\mathrm{Pd}_{3}(\mathrm{tmeda})_{3}(\mathbf{L 1})_{2}\right]^{6+},\left[\mathrm{Pd}(\mathbf{L 1})_{2}\right]^{2+}$, and $\left[\left(\mathrm{NO}_{3}\right)_{2} @ \mathrm{Pd}_{3}(\mathbf{L 1})_{4}\right]^{4+}$ are shown in Figure 4 (see Supporting Information File 1 for details). Geometry optimization and calculation of frequencies were performed using Gaussian 09 software package at the B3LYP/6-31G* level of theory [37]. Since the complex $\left[\mathrm{Pd}_{3}(\text { tmeda })_{3}(\mathbf{L 1})_{2}\right]^{6+}$ could not be prepared exclusively, we looked into the energetics of the system. The overall Gibbs free energies $(\Delta G)$ and the enthalpies $(\Delta H)$ for the formation of the trinuclear complex $\left[\mathrm{Pd}_{3}(\text { tmeda })_{3}(\mathbf{L 1})_{2}\right]^{6+}$ considering its formation from 1 equivalent of $\left[\mathrm{Pd}(\mathrm{tmeda})\left(\mathrm{NO}_{3}\right)_{2}\right]$ and 2 equivalents of $[\operatorname{Pd}(\text { tmeda })(\mathbf{L} 1)]^{2+}$ were found to be not feasible $\left(616.349 \mathrm{kcal} \mathrm{mol}^{-1}\right)$ and endothermic (+537.727 kcal mol$\left.{ }^{-1}\right)$, respectively (see Figure S71 and Table S3 in Supporting Information File 1). However, a small amount of the trinuclear complex was formed experimentally. Probably, the counter anions stayed in the hemi-cage part of the trinuclear structure making it somewhat feasible. A detailed investigation of solvent and counter anion might help.

\section{Complex-to-complex transformations: $\mathbf{3 a}$ versus $\mathbf{4 a}$}

The in situ prepared mononuclear complex $\left[\mathrm{Pd}(\mathbf{L 1})_{2}\right]\left(\mathrm{NO}_{3}\right)_{2}$ (3a) was found to be stable at room temperature for days in 
(i)

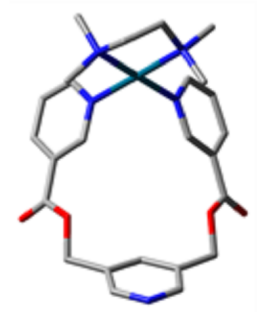

(ii)

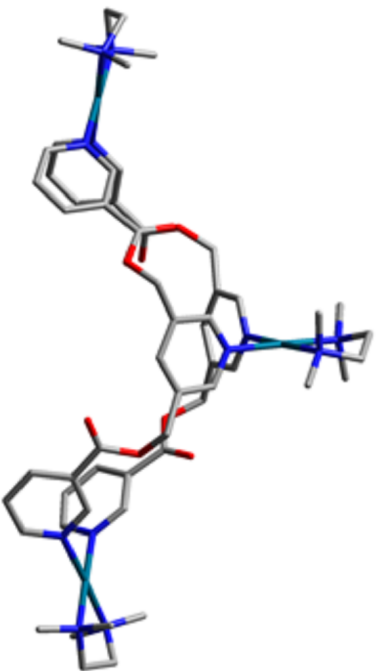

(iii)

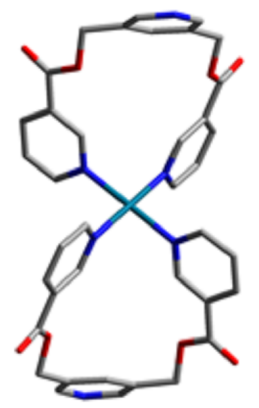

(iv)

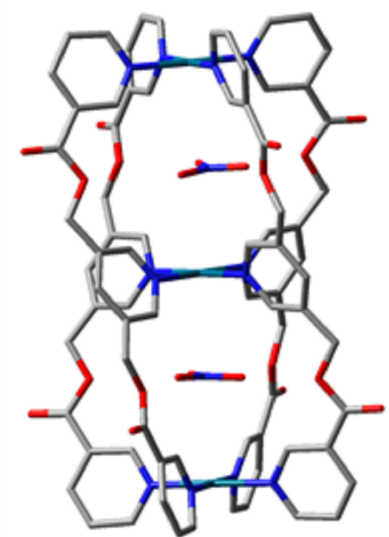

Figure 4: Energy-minimized structures of (i) $[\mathrm{Pd}(\text { tmeda })(\mathrm{L} 1)]^{2+}$, (ii) $\left[\mathrm{Pd}_{3}\left(\mathrm{tmeda}_{3}(\mathrm{~L} 1)_{2}\right]^{6+},\left(\right.\right.$ iii) $\left[\mathrm{Pd}(\mathrm{L} 1)_{2}\right]^{2+}$, and (iv) $\left[\left(\mathrm{NO}_{3}\right)_{2} @ \mathrm{Pd}_{3}(\mathrm{~L} 1)_{4}\right]^{4+}$. Hydrogen atoms are omitted for clarity, red, blue, grey and cyan colors represent oxygen, nitrogen, carbon and palladium, respectively.

DMSO- $d_{6}$ (Supporting Information File 1, Figure S43) but not upon heating. The ${ }^{1} \mathrm{H}$ NMR spectrum recorded after heating the solution at $90{ }^{\circ} \mathrm{C}$ for $24 \mathrm{~h}$ revealed decomplexation and signals for the free ligand were observed (Supporting Information File 1, Figure S44). In addition, the solution turned dark and dark particles were observed. Upon cooling the solution, the free ligand should have undergone complexation to form $\mathbf{3 a}$. However, no complexation was observed and it is assumed that palladium(II) got reduced to palladium(0). In another experiment, $\mathrm{Pd}\left(\mathrm{NO}_{3}\right)_{2}$ was added to a solution of $\mathbf{3} \mathbf{a}$ at a 2:1 ratio where upon complex-to-complex conversion was observed at room temperature or upon heating to afford $\mathbf{4 a}$ (Scheme 2(i)). With the appropriate amount of $\mathrm{Pd}\left(\mathrm{NO}_{3}\right)_{2}$ a complete formation of $4 \mathbf{a}$ was observed within $20 \mathrm{~min}$ at $\mathrm{rt}$ or $5 \mathrm{~min}$ at $90{ }^{\circ} \mathrm{C}$ (Supporting Information File 1, Figures S45 and S46).

On the other hand, the in situ prepared trinuclear complex 4a was found to be stable at room temperature as well as at $90{ }^{\circ} \mathrm{C}$ for days (Supporting Information File 1, Figures S47 and S48). The free ligand $\mathbf{L} 1$ was added to a solution of $\mathbf{4 a}$ in DMSO- $d_{6}$ at room temperature and the sample was monitored by ${ }^{1} \mathrm{H}$ NMR spectroscopy. The calculated amount of ligand was added to the

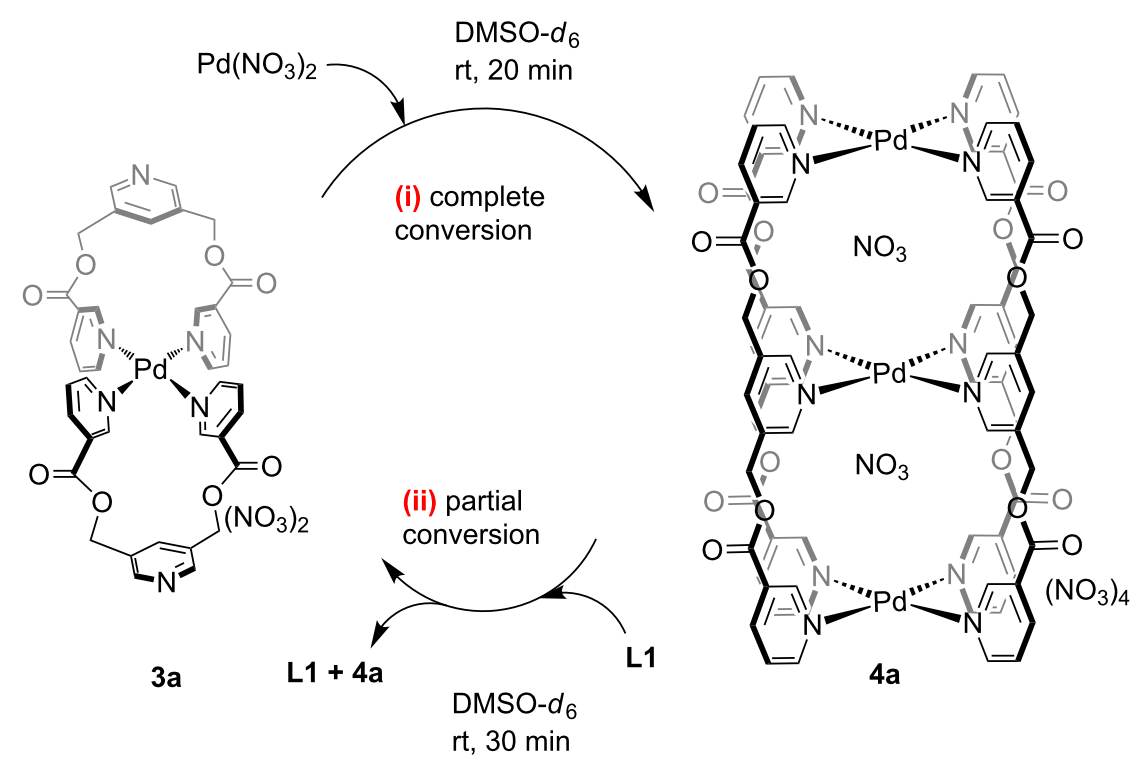

Scheme 2: Reorganization of (i) a mixture of $\mathrm{Pd}\left(\mathrm{NO}_{3}\right)_{2}$ and $3 \mathbf{a}$ at a 2:1 ratio leading to $4 \mathbf{a}$ with a complete conversion and (ii) a mixture of $\mathrm{L} 1$ and $4 \mathbf{a}$ at a 2:1 ratio leading to $3 \mathbf{a}$ but with a partial conversion. 
solution of $4 \mathbf{a}$ (at 2:1 ratio) to match the stoichiometric requirement for the formation of $\mathbf{3 a}$. Although the formation of $\mathbf{3 a}$ was observed, it remained only as a minor product, and the added ligand $\mathbf{L} \mathbf{1}$ was partially consumed. Thus, the unbound ligand remained in its free state along with $\mathbf{4 a}$. No further change was observed after $30 \mathrm{~min}$ (Supporting Information File 1, Figure S49). Heating of the reaction mixture did not help in further pushing the conversion towards the formation of 3a (Supporting Information File 1, Figure S50). Prolonged heating could not help because the complex $\mathbf{3 a}$ is unstable under such conditions. This provided additional support on the higher stability of 4a as compared to $\mathbf{3 a}$.

\section{Halide binding by the cavities of a double- decker cage}

The trinuclear complex $\left[\left(\mathrm{NO}_{3}\right)_{2} @ \mathrm{Pd}_{3}(\mathbf{L 1})_{4}\right]\left(\mathrm{NO}_{3}\right)_{4}(\mathbf{4 a})$ was prepared by mixing $\mathrm{Pd}\left(\mathrm{NO}_{3}\right)_{2}$ with ligand $\mathbf{L} 1$ at a 3:4 ratio (Scheme 3(i), also Scheme 1(iv)). Complexation of metal components like $\mathrm{Pd}\left(\mathrm{BF}_{4}\right)_{2}, \mathrm{Pd}\left(\mathrm{ClO}_{4}\right)_{2}$ or $\mathrm{Pd}(\mathrm{OTf})_{2}$ with $\mathbf{L 1}$ at a $3: 4$ ratio did not afford the analogous trinuclear complexes; rather the corresponding mononuclear complexes were formed and the uncomplexed palladium(II) remained in solution (Scheme 3(ii)).

Each of the two cavities of cage $\mathbf{4 a}$ is loaded with one $\mathrm{NO}_{3}{ }^{-}$. This phenomenon of $\mathrm{NO}_{3}{ }^{-}$encapsulation by a related isomeric

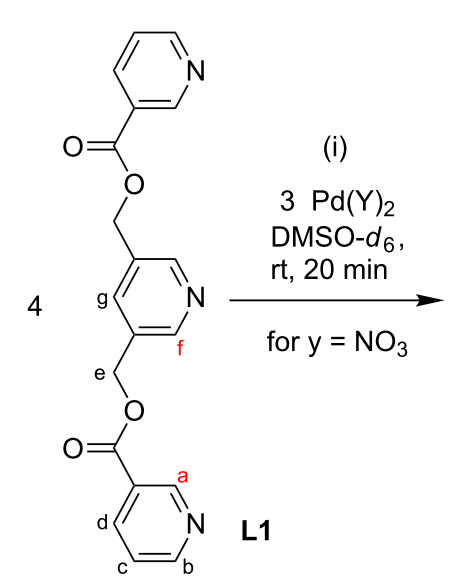

$\mathrm{Y}=\mathrm{BF}_{4}, \mathbf{3 b} ; \mathrm{ClO}_{4}, 3 \mathbf{c} ;$ OTf, 3d

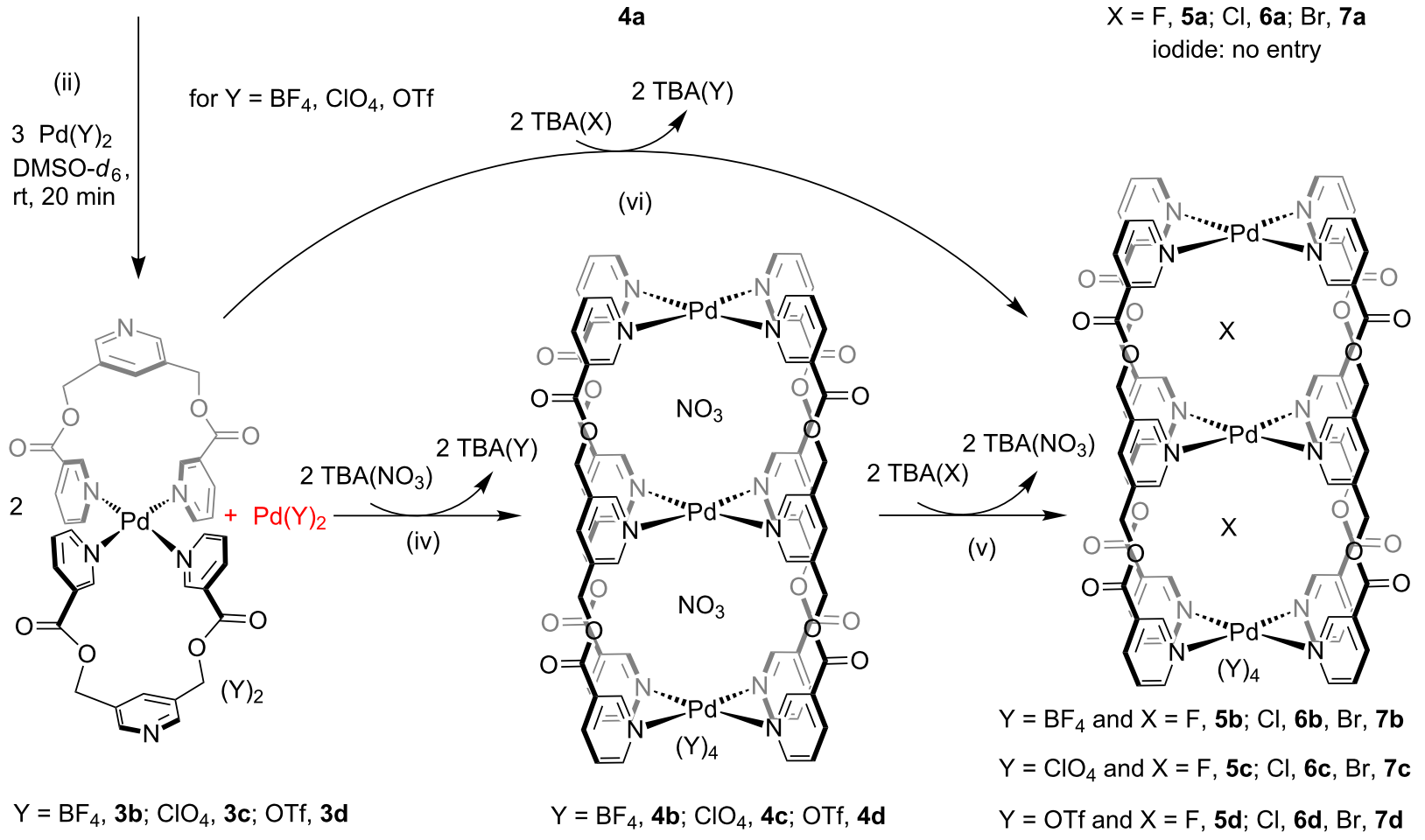

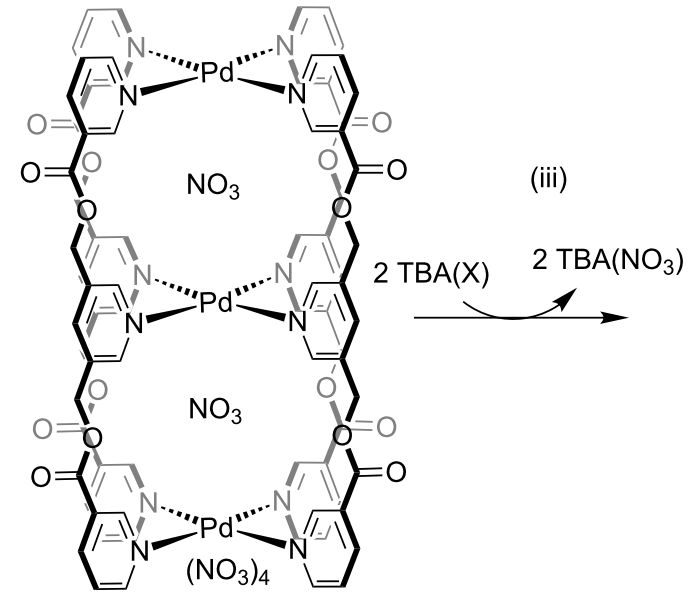

$4 a$

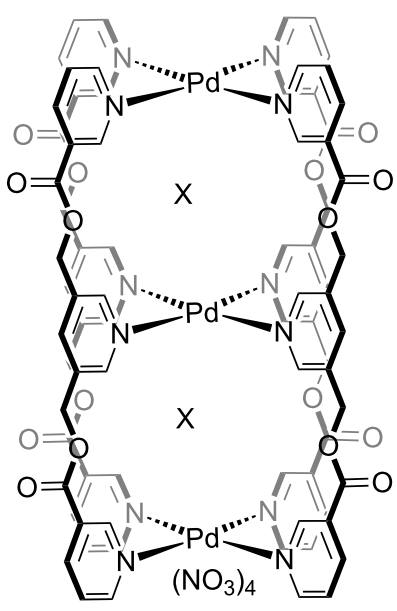

$\mathrm{X}=\mathrm{F}, \mathbf{5} \mathbf{a} ; \mathrm{Cl}, \mathbf{6 a} ; \mathrm{Br}, 7 \mathbf{a}$ iodide: no entry

Scheme 3: Halide $\left(\mathrm{F}^{-}, \mathrm{Cl}^{-}\right.$and $\mathrm{Br}^{-}$but not $\left.\mathrm{I}^{-}\right)$encapsulation by the cavities of the double-decker cage. 
cage was established by us earlier [22,23]. Halide recognition by the complex 4a through anion exchange was studied by portionwise addition of freshly prepared solutions of tetra- $n$ butylammonium halide, i.e., $\operatorname{TBA}(\mathrm{X})$ (where $\mathrm{X}$ stands for $\mathrm{F}^{-}, \mathrm{Cl}^{-}, \mathrm{Br}^{-}$and $\mathrm{I}^{-}$) in four separate experiments using DMSO- $d_{6}$ as the solvent. The anion exchange processes were monitored by ${ }^{1} \mathrm{H}$ NMR spectroscopy of the samples (Supporting Information File 1, Figures S51-S54). The addition of a portion of TBACl to the complex 4a resulted in a mixture of 4a, $\left[(\mathrm{Cl})\left(\mathrm{NO}_{3}\right) @ \mathrm{Pd}_{3}(\mathbf{L 1})_{4}\right]\left(\mathrm{NO}_{3}\right)_{4}\left(\mathbf{6} \mathbf{a}^{\prime}\right)$ and $\left[(\mathrm{Cl})_{2} @ \mathrm{Pd}_{3}(\mathbf{L 1})_{4}\right]\left(\mathrm{NO}_{3}\right)_{4}(\mathbf{6 a})$. With further addition of TBACl, the proportion of $\mathbf{6 a}$ increased at the cost of $\mathbf{4 a}$ and $\mathbf{6 a}$ ' to finally yield compound $\mathbf{6 a}$ as the only product. Similarly, the addition of $\mathrm{TBABr}$ initially produced a mixture of 4a, [(Br) $\left.\left(\mathrm{NO}_{3}\right) @ \mathrm{Pd}_{3}(\mathbf{L} \mathbf{1})_{4}\right]\left(\mathrm{NO}_{3}\right)_{4} \quad\left(\mathbf{7} \mathbf{a}^{\prime}\right)$ and $\left[(\mathrm{Br})_{2} @ \mathrm{Pd}_{3}(\mathbf{L 1})_{4}\right]\left(\mathrm{NO}_{3}\right)_{4}(\mathbf{7 a})$ with complex 7a as the exclusive final product. In the case of TBAF, initially there was no change observable except a slight broadening of the signals for $\mathrm{H}_{\mathrm{b}}$ and $\mathrm{H}_{\mathrm{c}}$. Further addition of TBAF led to the formation of $\left[(\mathrm{F})_{2} @ \mathrm{Pd}_{3}(\mathbf{L 1})_{4}\right]\left(\mathrm{NO}_{3}\right)_{4}(\mathbf{5 a})$ along with minor impurities. However, the addition of TBAI to $4 \mathbf{a}$ showed no changes and hence iodide encapsulation did not happen. The ${ }^{1} \mathrm{H}$ NMR spectra for the mixtures of products formed at intermediate and final stages are provided in Supporting Information File 1 (Figures S51-S54) and those of 4a, 5a, 6a and 7a are shown in Figure 5. The positions of the signals in the ${ }^{1} \mathrm{H}$ NMR spectra of these anion-encapsulated complexes are influenced by coordination of ligand L1 with palladium(II) and interaction of the encapsulated anion with the endohedrally oriented hydrogens of the cages.
Is iodide not capable of replacing the preexisting nitrate in a competition or iodide is not suited at all for the cavity irrespective of any competition? The following argument might answer this question. The complexation reaction shown in steps (ii) of Scheme 3 suggest that the presence of $\mathrm{BF}_{4}{ }^{-}, \mathrm{ClO}_{4}{ }^{-}$or OTf could not support the formation of the double-decker cage even though the required amount of palladium(II) was available. The addition of TBAI to any of these solutions containing $\mathrm{Pd}(\mathrm{Y})_{2}$ and $\mathbf{3 b}, \mathbf{3 c}$ or $\mathbf{3 d}$, respectively, did not lead to double-decker cages indicates that $\mathrm{I}^{-}$is not suited for the cavity. However, addition of $\mathrm{TBANO}_{3}, \mathrm{TBAF}, \mathrm{TBACl}$ and $\mathrm{TBABr}$ produced the corresponding anion encapsulated double-decker cages as shown in steps (iv), (v) and (vi) of Scheme 3. Representative ${ }^{1} \mathrm{H}$ NMR spectra for the conversion of $\mathbf{3} \mathbf{b}$ to corresponding products $\mathbf{4 b}, \mathbf{5 b}, \mathbf{6 b}$ and $\mathbf{7 b}$ are shown in Supporting Information File 1 (Figure S55).

The ${ }^{1} \mathrm{H}$ NMR spectral analysis of the two nitrate anions incorporating compound $4 \mathbf{a}$ discussed in an earlier section revealed downfield shifts of particular signals as compared to the free ligand $\mathbf{L} 1$ and the $\Delta \delta$ values were 1.42, 0.82 and $1.02 \mathrm{ppm}$ for the signals of $\mathrm{H}_{\mathrm{a}}, \mathrm{H}_{\mathrm{b}}$, and $\mathrm{H}_{\mathrm{f}}$, respectively. A similar comparison for the (i) two $\mathrm{F}^{-}$encapsulated compound 5a: $\Delta \delta=1.75$, 0.99 and $1.78 \mathrm{ppm}$ for $\mathrm{H}_{\mathrm{a}}, \mathrm{H}_{\mathrm{b}}$, and $\mathrm{H}_{\mathrm{f}}$, respectively), (ii) the two $\mathrm{Cl}^{-}$encapsulated compound 6a: $(\Delta \delta=1.91,1.01$ and $1.69 \mathrm{ppm}$ for $\mathrm{H}_{\mathrm{a}}, \mathrm{H}_{\mathrm{b}}$ and $\mathrm{H}_{\mathrm{f}}$, respectively), and (iii) the two $\mathrm{Br}^{-}$encapsulated compound 7a: $\left(\Delta \delta=2.24,1.02\right.$ and 1.74 ppm for $\mathrm{H}_{\mathrm{a}}, \mathrm{H}_{\mathrm{b}}$ and $\mathrm{H}_{\mathrm{f}}$, respectively) are in line with the expectation. Although fluoride $\left(\mathrm{F}^{-}\right)$could replace $\mathrm{NO}_{3}{ }^{-}$in $\mathbf{4 a}$ to afford complex $\mathbf{5 a}$, the complex 5a was found to be unstable and it decomposed

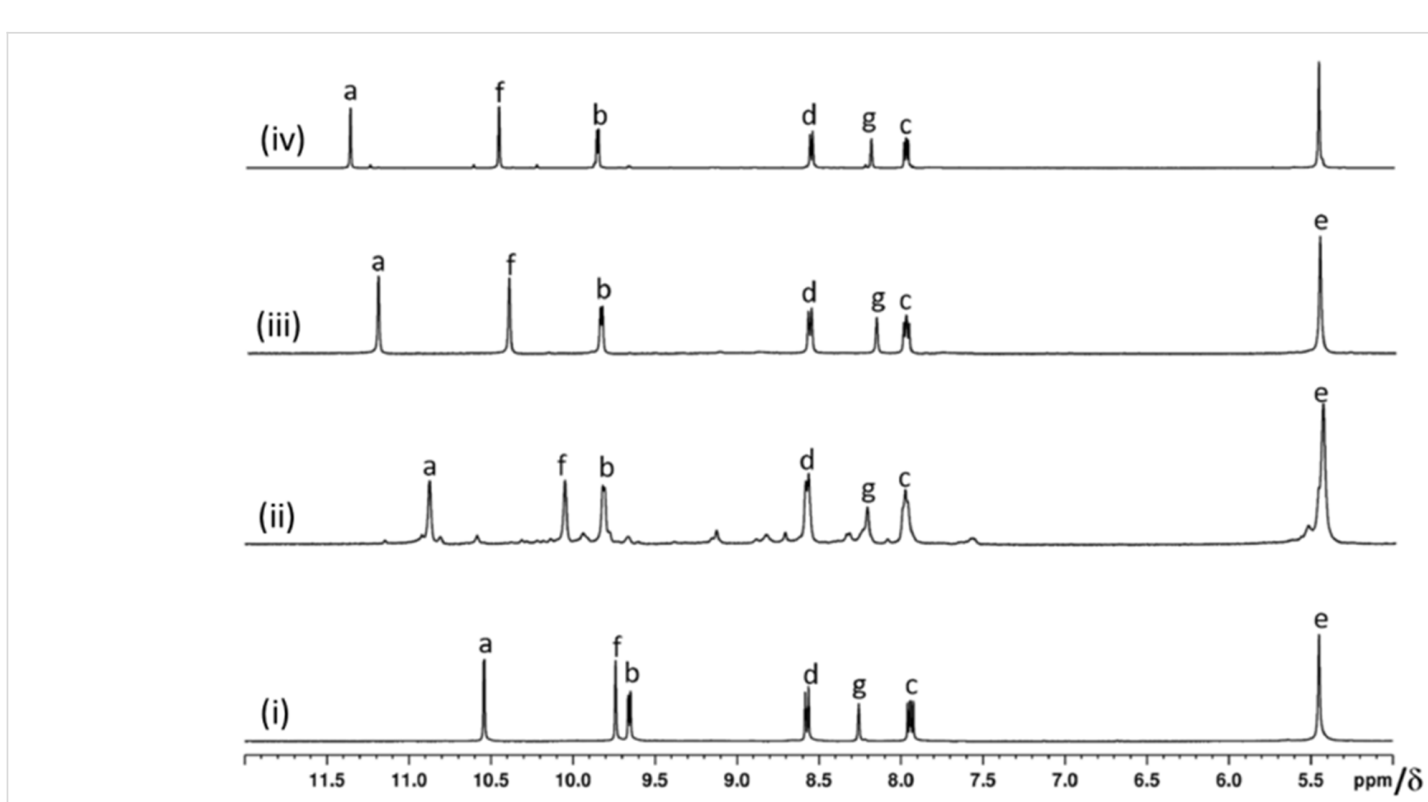

Figure 5: Partial ${ }^{1} \mathrm{H}$ NMR spectra at $400 \mathrm{MHz}$ in DMSO-d $d_{6}$ for (i) $\left[\left(\mathrm{NO}_{3}\right)_{2} @ \mathrm{Pd}_{3}(\mathrm{~L} 1)_{4}\right]\left(\mathrm{NO}_{3}\right)_{4}(\mathbf{4 a}),(\mathrm{ii})\left[(\mathrm{F})_{2} @ \mathrm{Pd}_{3}(\mathrm{L1})_{4}\right]\left(\mathrm{NO}_{3}\right)_{4}(\mathbf{5 a})$, (iii) $\left[(\mathrm{Cl})_{2} @ \mathrm{Pd}_{3}(\mathrm{~L} 1)_{4}\right]\left(\mathrm{NO}_{3}\right)_{4}(6 \mathrm{a})$ and (iv) $\left[(\mathrm{Br})_{2} @ \mathrm{Pd}_{3}(\mathrm{~L} 1)_{4}\right]\left(\mathrm{NO}_{3}\right)_{4}(7 \mathrm{a})$. 
within a few hours. Thus the ${ }^{1} \mathrm{H}$ NMR and ESIMS spectrum of 5a were recorded from freshly prepared samples. The complexes $4 \mathbf{a}, \mathbf{6 a}$ and $7 \mathbf{a}$ are quite stable and no decomposition was observed. Detailed characterization data of $4 \mathbf{a}-7 \mathbf{a}$ form a variety of NMR techniques are provided in Supporting Information File 1, Figures S56-S66.

The molecular compositions of the halide encapsulated complexes were confirmed by recording ESIMS data for the systems. The double halide encapsulated complexes $6 \mathbf{a}$ and 7a were detected. Also, one of the mixed halide-nitrate encapsulated complexes, i.e., 7a' was also detected.

The ESIMS spectrum of compound $\mathbf{6 a}$ (Supporting Information File 1, Figure S67) showed isotopic peak pattern at $\mathrm{m} / \mathrm{z}=$ 956.02 which corresponds to the cationic fragment $\left[6 \mathbf{a}-2 \mathrm{NO}_{3}\right]^{2+}$ that was formed due to the loss of two counter anions from 6a. The ESIMS spectrum of compound 7a (Supporting Information File 1, Figure S68) showed isotopic peak patterns at $m / z=645.99$ and at 468.99 which correspond to the cationic fragments $\left[7 \mathbf{a}-3 \mathrm{NO}_{3}\right]^{3+}$ and $\left[7 \mathbf{a}-4 \mathrm{NO}_{3}\right]^{4+}$ that are formed due to the loss of three and four units of counter anions from 7a. The ESIMS spectrum of compound 7a' (Supporting Information File 1, Figure S69) showed isotopic peak pattern at $m / z=991.51$ which corresponds to the cationic fragment $\left[7 \mathbf{a}^{\prime}-2 \mathrm{NO}_{3}\right]^{2+}$ that is formed due to the loss of two units of counter anions from 7a'. The experimental and theoretical peak patterns were found to be in agreement.

\section{Coordination complexes of L1 versus L2: ligand isomerism phenomenon}

As discussed in the introduction section "The definition of ligand isomerism includes metal complexes (at least two) having the same molecular formula but are composed of different structural isomers of the ligand." The complexes prepared in this work namely $[\mathrm{Pd}($ tmeda $)(\mathbf{L 1})]\left(\mathrm{NO}_{3}\right)_{2}(\mathbf{1 a})$, $\left[\mathrm{Pd}(\mathbf{L 1})_{2}\right]\left(\mathrm{NO}_{3}\right)_{2}(\mathbf{3 a}),\left[\left(\mathrm{NO}_{3}\right)_{2} @ \mathrm{Pd}_{3}(\mathbf{L 1})_{4}\right]\left(\mathrm{NO}_{3}\right)_{4}(\mathbf{4 a})$, and $\left[(\mathrm{X})_{2} @ \mathrm{Pd}_{3}(\mathbf{L 1})_{4}\right]\left(\mathrm{NO}_{3}\right)_{4} \mathbf{5 a}-\mathbf{7 a}$ fulfill the definition of ligand isomerism when compared with the reported complexes $[\mathrm{Pd}(\mathrm{tmeda})(\mathbf{L 2})]\left(\mathrm{NO}_{3}\right)_{2}(\mathbf{8 a}),\left[\mathrm{Pd}(\mathbf{L 2})_{2}\right]\left(\mathrm{NO}_{3}\right)_{2} \quad(\mathbf{1 0 a})$, $\left[\left(\mathrm{NO}_{3}\right)_{2} @ \mathrm{Pd}_{3}(\mathbf{L 2})_{4}\right]\left(\mathrm{NO}_{3}\right)_{4}(\mathbf{1 1 a})$, and $\left[(\mathrm{X})_{2} @ \mathrm{Pd}_{3}(\mathbf{L 2})_{4}\right]\left(\mathrm{NO}_{3}\right)_{4}$ 12a-14a, respectively. We have demonstrated ligand isomerism in $\mathrm{Pd}_{2} \mathrm{~L}_{4}$-type cages [29]. The present work demonstrates ligand isomerism in some complexes and more interestingly for the $\mathrm{Pd}_{3} \mathrm{~L}_{4}$-type double-decker coordination cages for the first time.

\section{Palladium(II)-based self-assembled com- plexes of ligands L1 and L2: a comparison}

The complexation behavior of $\mathbf{L} \mathbf{1}$ and $\mathbf{L} \mathbf{2}$ are broadly comparable. However, a closer look revealed certain differences. While complexation of cis-Pd(tmeda) $\left(\mathrm{NO}_{3}\right)_{2}$ with $\mathbf{L} \mathbf{1}$ produced the trinuclear complex $\left[\mathrm{Pd}_{3}(\text { tmeda })_{3}(\mathbf{L 1})_{2}\right]\left(\mathrm{NO}_{3}\right)_{6}(\mathbf{2 a})$, the ligand $\mathbf{L} 2$ did not afford the targeted $\left[\mathrm{Pd}_{3}(\mathrm{tmeda})_{3}(\mathbf{L 1})_{2}\right]\left(\mathrm{NO}_{3}\right)_{6}$ (9a). The complex $\left[\mathrm{Pd}(\mathbf{L 1})_{2}\right]\left(\mathrm{NO}_{3}\right)_{2}$ (3a) was unstable when heated in DMSO medium whereas the corresponding complex $\left[\mathrm{Pd}(\mathbf{L 2})_{2}\right]\left(\mathrm{NO}_{3}\right)_{2}(\mathbf{1 0 a})$ was stable under comparable conditions. The addition of two equivalents of $\mathbf{L} \mathbf{1}$ to a solution of $\left[\left(\mathrm{NO}_{3}\right)_{2} @ \mathrm{Pd}_{3}(\mathbf{L 1})_{4}\right]\left(\mathrm{NO}_{3}\right)_{4}(\mathbf{4 a})$ produced only a small amount of $\left[\mathrm{Pd}(\mathbf{L 1})_{2}\right]\left(\mathrm{NO}_{3}\right)_{2}(\mathbf{3 a})$ and the added ligand remained in solution. On the other hand, addition of the required amount of $\mathbf{L 2}$ to a solution of $\left[\left(\mathrm{NO}_{3}\right)_{2} @ \mathrm{Pd}_{3}(\mathbf{L 2})_{4}\right]\left(\mathrm{NO}_{3}\right)_{4}(\mathbf{1 1 a})$ resulted in complete transformation to complex $\left.\mathrm{Pd}(\mathbf{L 2})_{2}\right]\left(\mathrm{NO}_{3}\right)_{2}$ (10a). The $\mathrm{F}^{-}$encapsulated complex $\left[(\mathrm{F})_{2} @ \mathrm{Pd}_{3}(\mathbf{L 1})_{4}\right]\left(\mathrm{NO}_{3}\right)_{4}(\mathbf{5 a})$ decomposed within a few hours whereas $\left[(\mathrm{F})_{2} @ \mathrm{Pd}_{3}(\mathbf{L 2})_{4}\right]\left(\mathrm{NO}_{3}\right)_{4}$ (12a) was stable for a few hours. These differences are ascribed to the positional exchanged functionalities in the ligands $\mathbf{L 1}$ and L2. Probably, the coordination ability of the central pyridine ring is better than that of the terminal pyridine rings in case of L1. However, in the mononuclear complexes of $\mathbf{L} 1$ the central pyridine remained uncomplexed, which may be due to the formation of metallomacrocyclic rings. This behavior is not observed in the case of mononuclear complexes of L2. Thus, the mononuclear complexes of $\mathbf{L} \mathbf{1}$ are reluctant to form (e.g., from 4a and L1) and prone to decomposition. As far as trinuclear complex formation is concerned the central pyridine ring of $\mathbf{L 1}$ is in a relatively favorable situation, thus the complex 4 a could form and 3a was a kinetic product.

\section{Conclusion}

A set of mononuclear and trinuclear complexes were prepared through complexation of cis-protected palladium(II) and bare palladium(II) components with the new tridentate ligand L1. A variety of counter anions were employed to broaden the scope of the choice of metal components. Mononuclear complexes with PdL'L composition could be prepared easily, however, $\mathrm{Pd}_{3} \mathrm{~L}_{3} \mathrm{~L}_{2}$-type trinuclear complexes were obtained in only small amounts. Also, mononuclear complexes of $\mathrm{PdL}_{2}$ and trinuclear complexes of $\mathrm{Pd}_{3} \mathrm{~L}_{4}$-type compositions were prepared easily. The choice of the counter anion did not influence the formation of mononuclear complexes whereas the counter anion displayed a template role for the formation of trinuclear complexes, especially for $\mathrm{Pd}_{3} \mathrm{~L}_{4}$-type complexes. The anions helped to screen the charge repulsion between the palladium(II) ions. The complexation behavior of palladium(II) components with the ligand $\mathbf{L} 2$ have been reported earlier [23]. The similarities and differences in the complexation behaviors of the ligands $\mathbf{L 1}$ and $\mathbf{L} \mathbf{2}$ were highlighted. A qualitative comparison indicated that ligands $\mathbf{L} 1$ and $\mathbf{L} 2$ are well suited for the formation of trinuclear only and mononuclear/trinuclear complexes, respectively. The $\mathrm{Pd}_{3} \mathrm{~L}_{3} \mathrm{~L}_{2}$-type complexes could be prepared, though in small proportions, using ligand $\mathbf{L 1}$ but not L2. The ligands L1 and $\mathbf{L} \mathbf{2}$ are positional isomers (regioisomers) hence many of 
their complexes could be rightfully considered under ligand isomerism in coordination complexes.

\section{Experimental}

Synthesis of ligand L1: A mixture of pyridine-3,5diyldimethanol (282.6 mg, $2.03 \mathrm{mmol})$ and nicotinoyl chloride hydrochloride $(500.0 \mathrm{mg}, 4.06 \mathrm{mmol})$ in dry DCM $(50 \mathrm{~mL})$ was placed in a $100 \mathrm{~mL}$ round-bottomed flask. The flask was placed in an ice bath to cool the mixture followed by the dropwise addition of triethylamine $(2 \mathrm{~mL})$. Then, the reaction mixture was stirred at room temperature for $24 \mathrm{~h}$ followed by the addition of a saturated aqueous solution of sodium bicarbonate. The organic layer was separated and the solvent was evaporated using a rotavapor. The crude product was purified by column chromatography using EtOAc/hexane 8:2 to afford the product as white solid (507.3 $\mathrm{mg}$, isolated yield $71 \%$ ) after evaporation of the solvent and drying under vacuum. Mp $124{ }^{\circ} \mathrm{C}$; ${ }^{1} \mathrm{H}$ NMR $\left(500 \mathrm{MHz}, \mathrm{DMSO}-d_{6}, 300 \mathrm{~K}\right) \delta 9.13\left(\mathrm{dd}, J_{1}=2.8 \mathrm{~Hz}, J_{2}=\right.$ $\left.1.5 \mathrm{~Hz}, 1 \mathrm{H}, \mathrm{H}_{\mathrm{a}}\right), 8.83\left(\mathrm{dd}, J_{1}=6.5 \mathrm{~Hz}, J_{2}=3.2 \mathrm{~Hz}, 1 \mathrm{H}, \mathrm{H}_{\mathrm{b}}\right)$, $8.72\left(\mathrm{~d}, J=2.0 \mathrm{~Hz}, 1 \mathrm{H}, \mathrm{H}_{\mathrm{f}}\right), 8.34-8.32\left(\mathrm{~m}, 1 \mathrm{H}, \mathrm{H}_{\mathrm{d}}\right), 8.09(\mathrm{t}, J=$ $\left.2.0 \mathrm{~Hz}, 1 \mathrm{H}, \mathrm{H}_{\mathrm{g}}\right), 7.58-7.55\left(\mathrm{~m}, 1 \mathrm{H}, \mathrm{H}_{\mathrm{c}}\right), 5.47\left(\mathrm{~s}, 2 \mathrm{H}, \mathrm{H}_{\mathrm{e}}\right)$; ${ }^{13} \mathrm{C}$ NMR (100 MHz, DMSO- $\left.d_{6}, 300 \mathrm{~K}\right) \delta 164.59,153.88$, 150.12, 149.10, 137.01, 135.62, 131.46, 125.37, 123.97, 64.13; $\operatorname{ESIMS~}(\mathrm{m} / \mathrm{z}): 372.098[\mathrm{M}+\mathrm{Na}]^{+}$.

[Pd(tmeda)(L1)]( $\left.\mathrm{NO}_{3}\right)_{2}$ (1a): To a solution of cis$\mathrm{Pd}(\mathrm{tmeda})\left(\mathrm{NO}_{3}\right)_{2}(10.3 \mathrm{mg}, 0.03 \mathrm{mmol})$, in $3 \mathrm{~mL}$ of DMSO ligand $\mathbf{L 1}$ (10.5 mg, $0.03 \mathrm{mmol}$ ) was added. The reaction mixture was stirred at room temperature for $10 \mathrm{~min}$ to obtain a clear yellow solution. The product was precipitated by the addition of ethyl acetate $(10 \mathrm{~mL})$, separated by centrifugation, washed with acetone $(4 \mathrm{~mL})$ and dried under vacuum to afford complex 1a (16.8 mg, isolated yield 80\%). ${ }^{1} \mathrm{H}$ NMR (500 MHz, DMSO- $d_{6}$, $300 \mathrm{~K}) \delta 9.90\left(\mathrm{~d}, J=1.5 \mathrm{~Hz}, 1 \mathrm{H}, \mathrm{H}_{\mathrm{a}}\right), 9.35\left(\mathrm{dd}, J_{1}=1.0 \mathrm{~Hz}\right.$, $\left.J_{2}=5.8 \mathrm{~Hz}, 1 \mathrm{H}, \mathrm{H}_{\mathrm{b}}\right), 8.67\left(\mathrm{~s}, 1 \mathrm{H}, \mathrm{H}_{\mathrm{f}}\right), 8.54-8.52\left(\mathrm{~m}, 1 \mathrm{H}, \mathrm{H}_{\mathrm{d}}\right)$, $8.18\left(\mathrm{~s}, 1 \mathrm{H}, \mathrm{H}_{\mathrm{g}}\right), 7.85\left(\mathrm{dd}, J_{1}=7.9 \mathrm{~Hz}, J_{2}=5.8 \mathrm{~Hz}, 1 \mathrm{H}, \mathrm{H}_{\mathrm{c}}\right)$, $5.91-5.29\left(\mathrm{dd}, J_{1}=13.8 \mathrm{~Hz}, J_{2}=13.8 \mathrm{~Hz}, 2 \mathrm{H}, \mathrm{H}_{\mathrm{e}}\right) ;{ }^{13} \mathrm{C} \mathrm{NMR}$ $\left(125 \mathrm{MHz}, \mathrm{DMSO}-d_{6}, 300 \mathrm{~K}\right) \delta 164.50,154.60,151.91$, $147.21,140.92$, 133.03, 132.24, 129.41, 127.31, 63.41, 62.31 .

[Pd(L1) $\left.)_{2}\right]\left(\mathbf{N O}_{3}\right)_{2} \mathbf{( 3 a ) : ~ T o ~ a ~ s o l u t i o n ~ o f ~ l i g a n d ~} \mathbf{L 1}$ (20.9 mg, $0.06 \mathrm{mmol})$ in $3 \mathrm{~mL}$ of DMSO, $\mathrm{Pd}\left(\mathrm{NO}_{3}\right)_{2}(6.9 \mathrm{mg}, 0.03 \mathrm{mmol})$ was added and the reaction mixture was stirred for $10 \mathrm{~min}$ at room temperature to give a clear yellow solution. The product was precipitated by the addition of $10 \mathrm{~mL}$ of ethyl acetate. The pale yellow precipitate was separated by centrifugation, washed with acetone and dried under vacuum to afford complex 3a (18.6 mg, isolated yield 66\%). ${ }^{1} \mathrm{H}$ NMR (500 MHz, DMSO- $d_{6}$, $300 \mathrm{~K}) \delta 9.92\left(\mathrm{~s}, 1 \mathrm{H}, \mathrm{H}_{\mathrm{a}}\right), 9.30\left(\mathrm{~d}, J=5.3 \mathrm{~Hz}, 1 \mathrm{H}, \mathrm{H}_{\mathrm{b}}\right), 8.75(\mathrm{~d}$, $\left.J=1.3 \mathrm{~Hz}, 1 \mathrm{H}, \mathrm{H}_{\mathrm{f}}\right), 8.55-8.53\left(\mathrm{~m}, 1 \mathrm{H}, \mathrm{H}_{\mathrm{d}}\right), 8.31\left(\mathrm{~s}, 1 \mathrm{H}, \mathrm{H}_{\mathrm{g}}\right)$, $7.82\left(\mathrm{dd}, J_{1}=7.9 \mathrm{~Hz}, J_{2}=5.8 \mathrm{~Hz}, 1 \mathrm{H}, \mathrm{H}_{\mathrm{c}}\right), 5.63\left(\mathrm{~s}, 1 \mathrm{H}, \mathrm{H}_{\mathrm{e}}\right)$;
${ }^{13} \mathrm{C}$ NMR (125 MHz, DMSO- $\left.d_{6}, 300 \mathrm{~K}\right) \delta 162.43,154.57$, 151.59, 147.83, 141.30, 133.97, 132.31 129.57, 127.38, 63.86; $\operatorname{ESIMS~}(\mathrm{m} / \mathrm{z}): 866.10\left[\mathbf{3 a}-1 \mathrm{NO}_{3}\right]^{+} ; 402.05\left[\mathbf{3 a}-2 \mathrm{NO}_{3}\right]^{2+}$.

$\left[\left(\mathrm{NO}_{3}\right)_{2} @ \mathbf{P d}_{3}(\mathrm{L1})_{4}\right]\left(\mathrm{NO}_{3}\right)_{\mathbf{4}} \mathbf{( 4 a ) :}$ To a solution of ligand $\mathbf{L 1}$ $(14.0 \mathrm{mg}, 0.04 \mathrm{mmol})$ in $2 \mathrm{~mL}$ of DMSO, $\mathrm{Pd}\left(\mathrm{NO}_{3}\right)_{2}(7.0 \mathrm{mg}$, $0.03 \mathrm{mmol}$ ) in $1 \mathrm{~mL}$ of DMSO was added and the reaction mixture was stirred for $5 \mathrm{~min}$ at $90{ }^{\circ} \mathrm{C}$ to give a clear yellow solution. The product was precipitated by the addition of $10 \mathrm{~mL}$ of ethyl acetate. The pale yellow precipitate was separated by centrifugation, washed with acetone and dried under vacuum to afford the complex $4 \mathbf{a}\left(15.6 \mathrm{mg}\right.$, isolated yield 75\%). ${ }^{1} \mathrm{H} \mathrm{NMR}$ $\left(500 \mathrm{MHz}, \mathrm{DMSO}-d_{6}, 300 \mathrm{~K}\right) \delta 10.54\left(\mathrm{~d}, J=1.4 \mathrm{~Hz}, 1 \mathrm{H}, \mathrm{H}_{\mathrm{a}}\right)$, $9.74\left(\mathrm{~s}, 1 \mathrm{H}, \mathrm{H}_{\mathrm{f}}\right), 9.66\left(\mathrm{~d}, J=5.0 \mathrm{~Hz}, 1 \mathrm{H}, \mathrm{H}_{\mathrm{b}}\right), 8.58(\mathrm{~d}, J=$ $\left.8.0 \mathrm{~Hz}, 1 \mathrm{H}, \mathrm{H}_{\mathrm{d}}\right), 8.26\left(\mathrm{~s}, 1 \mathrm{H}, \mathrm{H}_{\mathrm{g}}\right), 7.95-7.93\left(\mathrm{~m}, 1 \mathrm{H}, \mathrm{H}_{\mathrm{c}}\right), 5.45$ $\left(\mathrm{s}, 1 \mathrm{H}, \mathrm{H}_{\mathrm{e}}\right) ;{ }^{13} \mathrm{C} \mathrm{NMR}\left(125 \mathrm{MHz}, \mathrm{DMSO}-d_{6}, 300 \mathrm{~K}\right) \delta 162.40$, 155.05, 153.19, 149.91, 141.88, 138.39, 133.83, 128.66, 127.68, 64.84; $\operatorname{ESIMS}(\mathrm{m} / \mathrm{z}): 982.04\left[4 \mathbf{a}-2 \mathrm{NO}_{3}\right]^{2+} ; 634.03$ $\left[4 \mathbf{a}-3 \mathrm{NO}_{3}\right]^{3+} ; 460.03\left[4 \mathbf{a}-4 \mathrm{NO}_{3}\right]^{4+}$.

\section{Supporting Information}

\section{Supporting Information File 1}

Experimental procedures, NMR, ESIMS data, and theoretical study.

[https://www.beilstein-journals.org/bjoc/content/ supplementary/1860-5397-15-109-S1.pdf]

\section{Acknowledgements}

D. K. C. thanks the Science and Engineering Research Board (SERB), the Department of Science and Technology, and the Government of India (Project No. EMR/2017/002262) for financial support. S. S. and B. S. R. thank CSIR and UGC, India for research fellowships, respectively. We thank IIT Madras for infrastructure and facilities.

\section{ORCID ${ }^{\circledR}$ iDs}

Dillip K. Chand - https://orcid.org/0000-0003-1115-0138

\section{References}

1. Cook, T. R.; Stang, P. J. Chem. Rev. 2015, 115, 7001-7045. doi:10.1021/cr5005666

2. Fujita, M.; Ogura, K. Bull. Chem. Soc. Jpn. 1996, 69, 1471-1482. doi:10.1246/bcsj.69.1471

3. Fujita, M. Chem. Soc. Rev. 1998, 27, 417-425. doi:10.1039/a827417z

4. Chambron, J.-C.; Sauvage, J.-P. New J. Chem. 2013, 37, 49-57. doi:10.1039/c2nj40555e

5. Debata, N. B.; Tripathy, D.; Chand, D. K. Coord. Chem. Rev. 2012, 256, 1831-1945. doi:10.1016/j.ccr.2012.04.001

6. Schmidt, A.; Casini, A.; Kühn, F. E. Coord. Chem. Rev. 2014, 275, 19-36. doi:10.1016/j.ccr.2014.03.037 
7. Chand, D. K.; Biradha, K.; Fujita, M. Chem. Commun. 2001, 1652-1653. doi:10.1039/b104853h

8. Clever, G. H.; Tashiro, S.; Shionoya, M. Angew. Chem., Int. Ed. 2009, 48, 7010-7012. doi:10.1002/anie.200902717

9. Han, M.; Michel, R.; He, B.; Chen, Y.-S.; Stalke, D.; John, M.; Clever, G. H. Angew. Chem., Int. Ed. 2013, 52, 1319-1323. doi:10.1002/anie.201207373

10. Zhu, R.; Lübben, J.; Dittrich, B.; Clever, G. H. Angew. Chem., Int. Ed. 2015, 54, 2796-2800. doi:10.1002/anie.201408068

11. Clever, G. H.; Shionoya, M. Chem. - Eur. J. 2010, 16, 11792-11796. doi:10.1002/chem.201002013

12. Kishi, N.; Li, Z.; Yoza, K.; Akita, M.; Yoshizawa, M. J. Am. Chem. Soc. 2011, 133, 11438-11441. doi:10.1021/ja2037029

13. Yamashina, M.; Yuki, T.; Sei, Y.; Akita, M.; Yoshizawa, M. Chem. - Eur. J. 2015, 21, 4200-4204. doi:10.1002/chem.201406445

14. Liao, P.; Langloss, B. W.; Johnson, A. M.; Knudsen, E. R.; Tham, F. S.; Julian, R. R.; Hooley, R. J. Chem. Commun. 2010, 46, 4932-4934. doi:10.1039/c0cc00234h

15. Kishi, N.; Li, Z.; Sei, Y.; Akita, M.; Yoza, K.; Siegel, J. S.; Yoshizawa, M. Chem. - Eur. J. 2013, 19, 6313-6320. doi:10.1002/chem.201204010

16. Bandi, S.; Chand, D. K. Chem. - Eur. J. 2016, 22, 10330-10335. doi:10.1002/chem.201602039

17. Yamashina, M.; Sei, Y.; Akita, M.; Yoshizawa, M. Nat. Commun. 2014, 5, No. 4662. doi:10.1038/ncomms5662

18. Lewis, J. E. M.; Gavey, E. L.; Cameron, S. A.; Crowley, J. D. Chem. Sci. 2012, 3, 778-784. doi:10.1039/c2sc00899h

19. Ganta, S.; Chand, D. K. Inorg. Chem. 2018, 57, 3634-3645. doi:10.1021/acs.inorgchem.7b02239

20. McMorran, D. A.; Steel, P. J. Angew. Chem., Int. Ed. 1998, 37, 3295-3297.

doi:10.1002/(sici)1521-3773(19981217)37:23<3295::aid-anie3295>3.0. co;2-5

21. McMorran, D. A.; Steel, P. J. Supramol. Chem. 2002, 14, 79-85. doi:10.1080/10610270290006600

22. Bandi, S.; Pal, A. K.; Hanan, G. S.; Chand, D. K. Chem. - Eur. J. 2014, 20, 13122-13126. doi:10.1002/chem.201403808

23. Bandi, S.; Samantray, S.; Chakravarthy, R. D.; Pal, A. K.; Hanan, G. S.; Chand, D. K. Eur. J. Inorg. Chem. 2016, 2816-2827. doi:10.1002/ejic.201600259

24. Vasdev, R. A. S.; Preston, D.; Crowley, J. D. Chem. - Asian J. 2017, 12, 2513-2523. doi:10.1002/asia.201700948

25. Preston, D.; Lewis, J. E. M.; Crowley, J. D. J. Am. Chem. Soc. 2017, 139, 2379-2386. doi:10.1021/jacs.6b11982

26. Zhu, R.; Regeni, I.; Holstein, J. J.; Dittrich, B.; Simon, M.; Prévost, S.; Gradzielski, M.; Clever, G. H. Angew. Chem., Int. Ed. 2018, 57, 13652-13656. doi:10.1002/anie.201806047

27. Fujita, M.; Yu, S.-Y.; Kusukawa, T.; Funaki, H.; Ogura, K.; Yamaguchi, K. Angew. Chem., Int. Ed. 1998, 37, 2082-2085. doi:10.1002/(sici)1521-3773(19980817)37:15<2082::aid-anie2082>3.0. co;2-0

28. Fujita, M.; Oguro, D.; Miyazawa, M.; Oka, H.; Yamaguchi, K.; Ogura, K. Nature 1995, 378, 469-471. doi:10.1038/378469a0

29. Qin, Z.; Jennings, M. C.; Puddephatt, R. J. Inorg. Chem. 2003, 42, 1956-1965. doi:10.1021/ic020322z

30. Troff, R. W.; Hovorka, R.; Weilandt, T.; Lützen, A.; Cetina, M.; Nieger, M.; Lentz, D.; Rissanen, K.; Schalley, C. A. Dalton Trans. 2012, 41, 8410-8420. doi:10.1039/c2dt30190c

31. Harris, K.; Sun, Q.-F.; Sato, S.; Fujita, M. J. Am. Chem. Soc. 2013, 135, 12497-12499. doi:10.1021/ja4043609
32. Yu, H.-J.; Liu, Z.-M.; Pan, M.; Wu, K.; Wei, Z.-W.; Xu, Y.-W.; Fan, Y.-N.; Wang, H.-P.; Su, C.-Y. Eur. J. Inorg. Chem. 2018, 80-85. doi:10.1002/ejic.201701319

33. Preston, D.; McNeill, S. M.; Lewis, J. E. M.; Giles, G. I.; Crowley, J. D. Dalton Trans. 2016, 45, 8050-8060. doi:10.1039/c6dt00133e

34. Dasary, H.; Jagan, R.; Chand, D. K. Inorg. Chem. 2018, 57, 12222-12231. doi:10.1021/acs.inorgchem.8b01884

35. Mateescu, M.; Nuss, I.; Southan, A.; Messenger, H.; Wegner, S. V.; Kupka, J.; Bach, M.; Tovar, G. M. E.; Boehm, H.; Laschat, S. Synthesis 2014, 46, 1243-1253. doi:10.1055/s-0033-1338614

36. Dasary, H.; Jagan, R.; Chand, D. K. Chem. - Eur. J. 2015, 21 , 1499-1507. doi:10.1002/chem.201405255

37. Gaussian 09, Revision A.02; Gaussian, Inc.: Wallingford, CT, 2009.

\section{License and Terms}

This is an Open Access article under the terms of the Creative Commons Attribution License

(http://creativecommons.org/licenses/by/4.0). Please note that the reuse, redistribution and reproduction in particular requires that the authors and source are credited.

The license is subject to the Beilstein Journal of Organic Chemistry terms and conditions: (https://www.beilstein-journals.org/bjoc)

The definitive version of this article is the electronic one which can be found at: doi:10.3762/bjoc. 15.109 